\title{
PEMBELAJARAN BERBASIS KOMPETENSI BAGI PENGUSAHA KULINER
}

\author{
Dyah Kusumastuti \\ Dosen Fakultas Bisnis dan Manajemen \\ Universitas Widyatama \\ e-mail:dyahk05@gmail.com \\ Friday Fitricia Nur \\ Fakultas Bisnis dan Manajemen \\ Universitas Widyatama
}

\begin{abstract}
Entrepreneurship its meaning two things: entrepreneurship as a career opportunity, or as competency. This study aims to analyze the needs of culinary competencies for successful entrepreneurs have the superior performance and how entrepreneurial learning competency for culinary entrepreneurs . Research Methods by doing Competency Based Interview with models of entrepreneurship competencies include : Achievement, Thinking and Problem Solving, Personal Maturity, Influence, Directing \& Controlling, Orientation to others of the 18 samples of culinary successful entrepreneur in the city and around Bandung - West Java . The finding that there is a need for competency 6 competencies and 14 culinary skills . Furthermore, Competency Based Learning ( CBL ) starting by identifying Skills Competency, Competency Based Learning Requirements ( ( CBLRs) and lessons are required. Competency evaluation conducted by Competency Based Assessment ( CBA) of " behavior that arises from the CBL . CBL needs to be done to stimulate entrepreneurial culinary talent and motivate to become entrepreneurs and to develop new innovation that will create jobs, create economic and social wealth. As the government's accelerated learning should be the initiator for building entrepreneurial learning culinary that can be accessed by culinary entrepreneurs which is required to develop competency and stimulate innovation .
\end{abstract}

Key Word: Learning, Competency, Entrepreneurship, Culinary 


\section{Pendahuluan}

Dinamika zaman terus bergulir dengan berbagai perubahan kebutuhan . Seperti makanan dan minuman menjadi industri yang tidak sekedar menghasilkan makanan atau kuliner untuk kebutuhan biologis namun menjadi suatu usaha bisnis yang memerlukan kreativitas dan inovasi serta menjadi sebuah gaya hidup baru di kalangan masyarakat. Pangan berubah menjadi sebuah industri kuliner yang memberikan tidak hanya cita rasa tapi juga kebutuhan lain manusia untuk bersosialisasi maupun beraktualisasi. Industri kuliner yang berkembang saat ini juga menyediakan ruang bagi pelanggan untuk bisa berkumpul dengan komunitasnya melalui layanan ruangan maupun jasa lainnya. Dari hasil data pengeluaran, diperkirakan 19 persen dan 16 persen dari pengeluaran wisatawan mancanegara dan wisatawan nusantara adalah untuk restoran dan kuliner. Sehingga realitas untuk membuka peluang bisnis kuliner ini cukup menjanjikan.. Loyalitas konsumen kuliner merupakan keuntungan terbesar bagi para pengusaha. Jadi tidak mengherankan bila loyalitas tersebut dijadikan target utama dalam berbisnis. Pertumbuhan industri kuliner saat ini tumbuh sangat subur dari tahun ke tahun, seperti data dibawah ini

Tabel 1. Perkembangan Usaha Restoran / Rumah Makan Berskala Menengah Dan Besar Tahun 2007 2010

\begin{tabular}{|c|c|c|c|}
\hline \multirow{2}{*}{ Tahun } & \multicolumn{2}{|c|}{ Usaha/Perusahaan } & \multirow{2}{*}{ Rata-Rata tenaga kerja } \\
\cline { 2 - 3 } & Jumlah & Pertumbuhan (\%) & \\
\hline 2007 & 1,615 & & 27 \\
\hline 2008 & 2,235 & 38.39 & 27 \\
\hline 2009 & 2,704 & 20.98 & 27 \\
\hline 2010 & 2,916 & 7.84 & 27 \\
\hline
\end{tabular}

Sumber : Kementerian Pariwisata dan Ekonomi Kreatif, 2013

Sumbangan atau kontribusi sektor kuliner yang masuk dalam kategori Perdagangan, Hotel dan Restoran dalam PDB juga cukup besar. Tiga sektor utama pembentukan PDB pada tahun 2008 - 2012 adalah Sektor Pertanian; Industri Pengolahan; dan Perdagangan, Hotel, dan Restoran. Ketiga sektor tersebut mempunyai peran lebih dari separuh dari total perekonomian yaitu sebesar 56,3\% pada tahun 2008, 55,0\% (2009), 53,8\% (2010) dan 52,8\% (2011) serta 52,3\%.

Sumber :Perkembangan Usaha Restoran/ Rumah Makan Berskala Menengah dan Besar Tahun 2007 - 2010 , diakses dari http://www.budpar.go.id/userfiles/file/rekaprestoran2007-2010.pdf

Peran strategis industri kuliner bagi pertumbuhan ekonomi,http://gopanganlokal. miti.or.id/index.php/peran-strategis-industri-kuliner-bagi- pertumbuhan-ekonomi)

Masuknya industri kuliner ke dalam bagian dari pengembangan industri kreatif di Indonesia merupakan kesadaran dari pemerintah akan besarnya potensi yang ada didalamnya. Selain karena jumlah penduduk Indonesia sebagai pasar domestik yang besar, Indonesia pun kaya akan keragaman lokal, yaitu beraneka makanan traditional di tiap daerah. Pertumbuhan restoran atau usaha makanan di beberapa daerah di Indonesia semakin memperjelas hal ini. 


\section{Industri Kuliner mendorong Pertumbuhan Pariwisata Indonesia}

Dari data BPS (2012), beberapa Provinsi di Indonesia merupakan daerah yang mempunyai industri kuliner cukup besar. DKI Jakarta jumlahnya hingga ribuan. Untuk daerah lain, potensi kuliner lokal masih banyak. Oleh sebab itu, ke depan sektor kuliner masih akan terus berkembang asalkan potensi lokal ini terus diberdayakan atau difasilitasi.

Pentingnya inovasi menjadi kunci untuk tetap survive dan langgeng, Pendekatan kompetensi menjadi semakin populer untuk memahami keberhasilan pengusaha/entrepreneur hal ini termasuk bagaimana seorang pengusaha bisa berhasil mulai dari mereka memulai bisnis, perencanaan dan pembiayaan, manajemen, pemasaran/penjualan, periklanan dan promosi penjualan, merchandising, pembiayaan dan akuntansi, hubungan personil, pembelian, produksi, fasilitas dan peralatan, dan risiko pengendalian.

Untuk itu perlu dianalisis kebutuhan Kompetensi Pengusaha Kuliner agar mereka berhasil memilki kinerja yang superior, sehingga akan berdampak pada pertumbuhan ekonomi local dan mendorong pertumbuhan pariwisata di Indonesia.

Spencer (1993) mengutarakan bahwa adanya perbedaan kompetensi antara seseorang yang memilki kinerja superior dan kinerja biasa, yang mana diidentifikasi menjadi kompetensi pembeda ( differentiating) antara "superior performance dan " average performer " . Sehingga perlu dianalisis kompetensi pembeda diantara pengusaha kuliner yang kinerja superior dan biasa. Selanjutnya dari Kompetensi pembeda yang menyebabkan kinerrja unggul ini ini kemudian dijadikan bahan pelatihan dan pembelajaran bagi pengusaha kuliner. Kompetensi pengusaha diidentifikasi sebagai entrepreneurship competency. Dalam Hu (2010), menurut McLagan (1996), model kompetensi dapat digunakan pelatihan desain kurikulum, rekrutmen, seleksi dan penilaian, pembinaan,konseling dan mentoring, pengembangan karir dan perencanaan kesuksesan. McLagan (1997) menyatakan bahwa kompetensi terkait dengan tugas pekerjaan, hasil dan output, dan karakteristik orang yang melakukan pekerjaan. Usaha restoran yang sukses membuat berulang dan pelanggan loyal dengan menyediakan pengalaman yang tak terlupakan.

Dengan harapan temuan kompetensi dapat digunakan sebagai pembelajaran agar para pengusaha kuliner yang semakin hari pertumbuhannya menjadi pesat dapat langgeng serta sudah saatnya kuliner Indonesia go internasional yang beroperasi di berbagai belahan dunia karena itu menjadi sarana yang efektif untuk diplomasi kuliner sekaligus mempromosikan negara. Dari uraian diatas diidentifikasi rumusan masalah adalah Kompetensi apa yang menjadi pembeda pengusaha kuliner yang kinerjanya unggul/superior dan bagaimana kompetensi pembeda tersebut dibelajarkan ke pengusaha kuliner ?

\section{Sehingga Penelitian ini bertujuan untuk menemukan}

Kompetensi pembeda antara pengusaha kuliner yang memilki kinerja unggul dan biasa , dilihat dari kompetensi Achievement, Thinking and Problem Solving , Personal Maturity, Influence, Directing \& Controlling, Orientation to others dan mengembangkan model pembelajaran dari kompetensi pembeda tersebut untuk peningkatan kompetensi Kewirausahaan bagi pengusaha kuliner 


\section{Studi Pustaka}

Wirausahawan atau Pengusaha adalah seseorang yang menciptakan bisnis baru sebagai pendiri ; pengusaha adalah orang yang menemukan sebuah ide bisnis untuk perusahaan, dan emungkinkan ide menjadi bisnis baru sehingga pengusaha pendekatannya adalah orang yang menciptakan bisnis/ide baru sebagai pendiri dan memiliki kepemilikan tertentu.

Fakta bahwa Kinerja individu di tempat kerja sangat dipengaruhi oleh kompetensi-kompetensi yang dimilikinya, maka sudah merupakan kebutuhan organisasi untuk mengintegrasikan konsep kompetensi dalam sistem manajemen sumber daya perusahaan (Spencer, 1993; Berger \& Berger. 2004; Kusumastuti ,D 2011).

Kewirausahaan adalah kemampuan untuk menempatkan ide-ide ke dalam tindakan yang dapat meliputi kreativitas, inovasi dan risiko mengambil, serta kemampuan untuk merencanakan dan melaksanakan proyek kegiatan untuk mewujudkan tujuan. Hal ini merupakan tantangan untuk mengubah konsep diri dan harga diri serta perilaku mereka dan memberi mereka alat untuk memiliki kesempatan yang adil untuk menjadi entrepreneur atau intrapreneur di sebuah perusahaan yang ada. Dalam menghadapi meningkatnya persaingan, bisnis kuliner harus mampu untuk tetap inovatif dan menarik pelanggan baru dengan memuaskan tuntutan mereka yang semakin canggih dan berubah. Konsumen khususnya mencari pengalaman baru dan unik. Untuk memenuhi tantangan tersebut baru-baru ini muncul gagasan dari para ahli untuk peningkatan kemampuan SDM yang lebih menekankan pada inovasi dalam industri jasa kuliner, bahkan pada gagasan kreativitas kuliner (Horng \& Hu, 2008), dan tentang pentingnya inovasi kompetensi (Fisscher, Visscher, Pearson, \& Weisenfeld, 2001 dalam Horng \& $\mathrm{Hu}$,2010). Dalam Hu (2010), Ulrich (1996) menyatakan bahwa pemahaman sumber daya manusia (SDM) melalui kompetensi merupakan inti dari profesi SDM dan SDM dalam perusahaan menjadi agen perubahan. $\mathrm{Hu}$ (2010), dalam penelitian menekankan pentingnya pendekatan kompetensi berinovasi industri perhotelan menghadapi meningkatnya persaingan. Untuk memenuhi tantangan ini bisnis kuliner perlu menempatkan bahwa inovasi merupakan kunci untuk menjadi "Sustainable Competitive advantage“"

\section{Studi Kompetensi Kewirausahaan}

Kewirausahaan telah berkembang dari sebuah subdisipline studi manajemen yang menyangkut sebagai proses sosial, menyiratkan kemampuan untuk mengenali, memanfaatkan, dan mengambil risiko dalam merebut peluang kewirausahaan, dan merupakan aktivitas sosial, yang melibatkan pribadi kontak dalam jaringan sosial.

Berdasarkan teori sistem sosial, pengusaha menggunakan empat jenis fungsi : tujuan pencapaian, pemeliharaan pola, jaringan sosial dan optimasi ekonomi untuk mengembangkan bisnis.

Untuk melakukan perannya dengan sukses. menekankan bidang kompetensi yang diperlukan untuk keberhasilan usaha kecil, termasuk: memulai bisnis, perencanaan dan penganggaran, manajemen, pemasaran / penjualan, periklanan dan promosi penjualan, merchandising, pembiayaan dan akuntansi, hubungan personil, pembelian, produksi, fasilitas dan peralatan, dan risiko pengendalian, melibatkan keseimbangan analitis, kemampuan kreatif, dan praktis. kemampuan untuk mengenali dan menganalisa peluang pasar, kemampuan untuk berkomunikasi, mengidentifikasi mental, membujuk dan berdiskusi dengan semua pihak di lingkungan bisnis, dan kemampuan untuk membangun jaringan serta termasuk sikap, nilai, 
kepercayaan, pengetahuan, keterampilan, kemampuan, kepribadian, kebijaksanaan, keahlian (sosial, teknis, manajerial), pola pikir dan kecenderungan perilaku.

\section{Hubungan Kompetensi \& kinerja}

Kompetensi yang dikemukakan oleh Spencer (1993), Boyatzis (2008), Shema S ( 2007) merupakan suatu karakteristik dasar individu yang memiliki hubungan kausal atau sebab akibat dengan kriteria yang dijadikan acuan untuk berperformansi superior di tempat kerja atau pada situasi tertentu.

\section{Hubungan Kausal}

Motif, sifat bawaan dan konsep diri memprediksikan keahlian yang akhirnya akan memprediksikan performansi kerja seperti terlihat pada gambar di bawah ini :

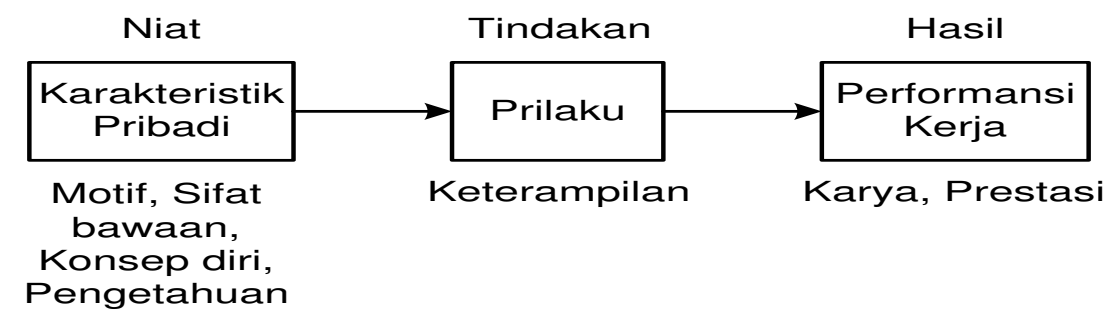

\section{Gambar 1. Hubungan Kausal Kompetensi dan prestasi}

( Sumber : Spencer \& Spencer,1993)

Tindakan atau perilaku (behavior) termasuk pemikiran, dimana pemikiran berasal dan prediksi behavior. Misalnya motif, perencanaan atau pemikiran pemecahan masalah.

Kriteria yang sering digunakan dalam studi kompetensi adalah :

Spencer and Spencer (1993), membagi kompetensi menjadi 2 (dua) kategori yaitu "threshold competencies" dan "differentiating compentencies". Threshold competencies adalah karakteristik utama yang harus dimiliki oleh seseorang agar dapat melaksanakan pekerjaannya, sementara differentiating competencies adalah karakteristik yang dimiliki seseorang berkinerja superior yang membedakannya dengan yang lain.

\section{Performansi Superior.}

Kriteria ini ditentukan dengan ukuran kinerja satu standar deviasi di atas rata-rata, level ini dicapai oleh 1 dari 10 orang dalam situasi kerja yang diberikan. Satu standar deviasi digunakan sebagai acuan dengan alasan:

Beberapa studi menunjukan nilai ekonomis level performansi terhadap organisasi

Untuk meningkatkan performansi, organisasi harus menggunakan karakteristik performansi superior sebagai dasar seleksi dan pengembangan pekerja. Kegagalan untuk melaksanakannya disebabkan kesalahan penentuan level performansi rata-rata organisasi. 


\section{Performansi Efektif.}

Kriteria ini merupakan level kinerja minimum yang dapat diterima dalam pekerjaan, dalam praktek sehari-hari performansi efektif sering diambil pada tingkat prestasi rata-rata atau disebut sebagai kinerja rata rata.

Konsep kinerja dalam gambar 2 dapat dijelaskan bahwa kinerja diyakini terjadi ketika 3 aspek meliputi kemampuan seseorang atau bakat konsisten dengan kebutuhan tuntutan kerja dan lingkungan organisasi (Boyatzis, 1982). Bakat orang tersebut digambarkan oleh nya: nilai-nilai, visi, dan filosofi pribadi; pengetahuan, kompetensi, karir dalam pekerjaan; kepentingan; dan gaya. Kebutuhan Tuntutan pekerjaan merupakan tanggung jawab, peran dan tugas yang perlu dilakukan. Aspek lingkungan organisasi yang diperkirakan memiliki dampak penting pada pewujudan kompetensi dan/atau desain pekerjaan sebuah peran meliputi: budaya dan iklim, struktur dan sistem, jatuh tempo dari industri dan posisi strategis di dalamnya, dan aspek ekonomi, politik, sosial, lingkungan, dan agama lingkungan sekitar organisasi.

Dari hasil penelitian yang dipublikasikan selama 30 tahun terakhir ini menunjukkan tampaknya membutuhkan tiga cluster kebiasaan perilaku kompetensi yang membedakan mencapai kinerja yang luar biasa, kompetensi tersebut adalah: (1) keahlian dan pengalaman (2) pengetahuan (yaitu deklaratif, prosedural, fungsional dan metakognitif) adalah ambang kompetensi, dan (3) berbagai macam kompetensi kognitif dasar, seperti memori dan deduktif penalaran adalah kompetensi ambang batas.

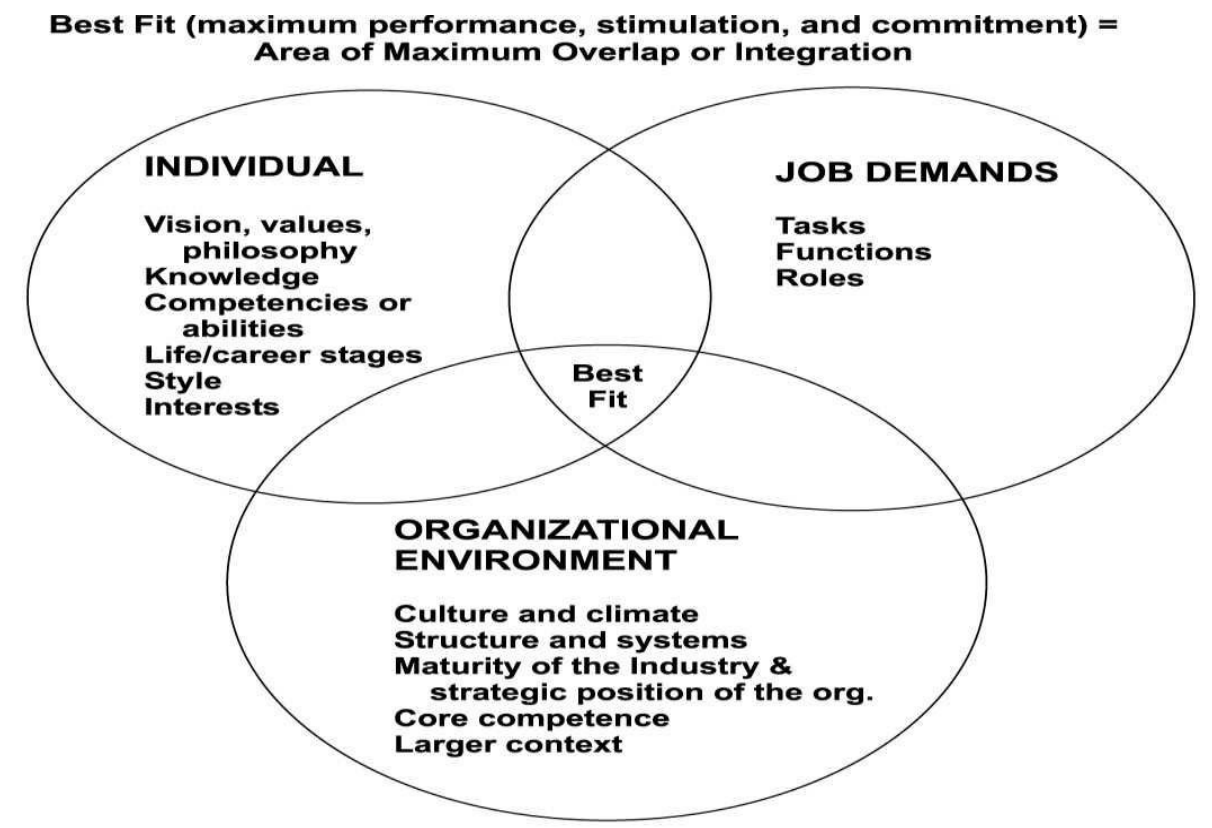

Source: Boyatzis $(1982,2008)$

\section{Gambar 2 :Best Fit}

Sikap dan nilai sama dengan kepercayaan diri, dapat diubah dengan pelatihan, psikoterapi, dan atau pengalaman positif sekalipun dengan waktu dan kesulitan yang lebih besar. Beberapa organisasi menyeleksi aparatur berdasarkan pada pengetahuan yang nampak dan keahlian dengan mengasumsikan bahwa motif utama dan sifat akan dapat ditumbuhkan dengan manajemen yang baik. Hal ini seringkali membawa organisasi pada biaya yang tidak efisien. Pada pekerjaan yang kompleks, kompetensi inti (motif, sikap bawaan dan tata nilai) ditemukan 
relatif lebih penting dalam memprediksi performansi superior dibanding IQ, kepandaian atau prestasi akademis.

Berdasarkan Spencer and Spencer (1993), Model Kompetensi secara umum pengusaha dapat digambarkan di tabel 2 berikut yaitu:

Tabel 2. Model Kompetensi secara umum pengusaha

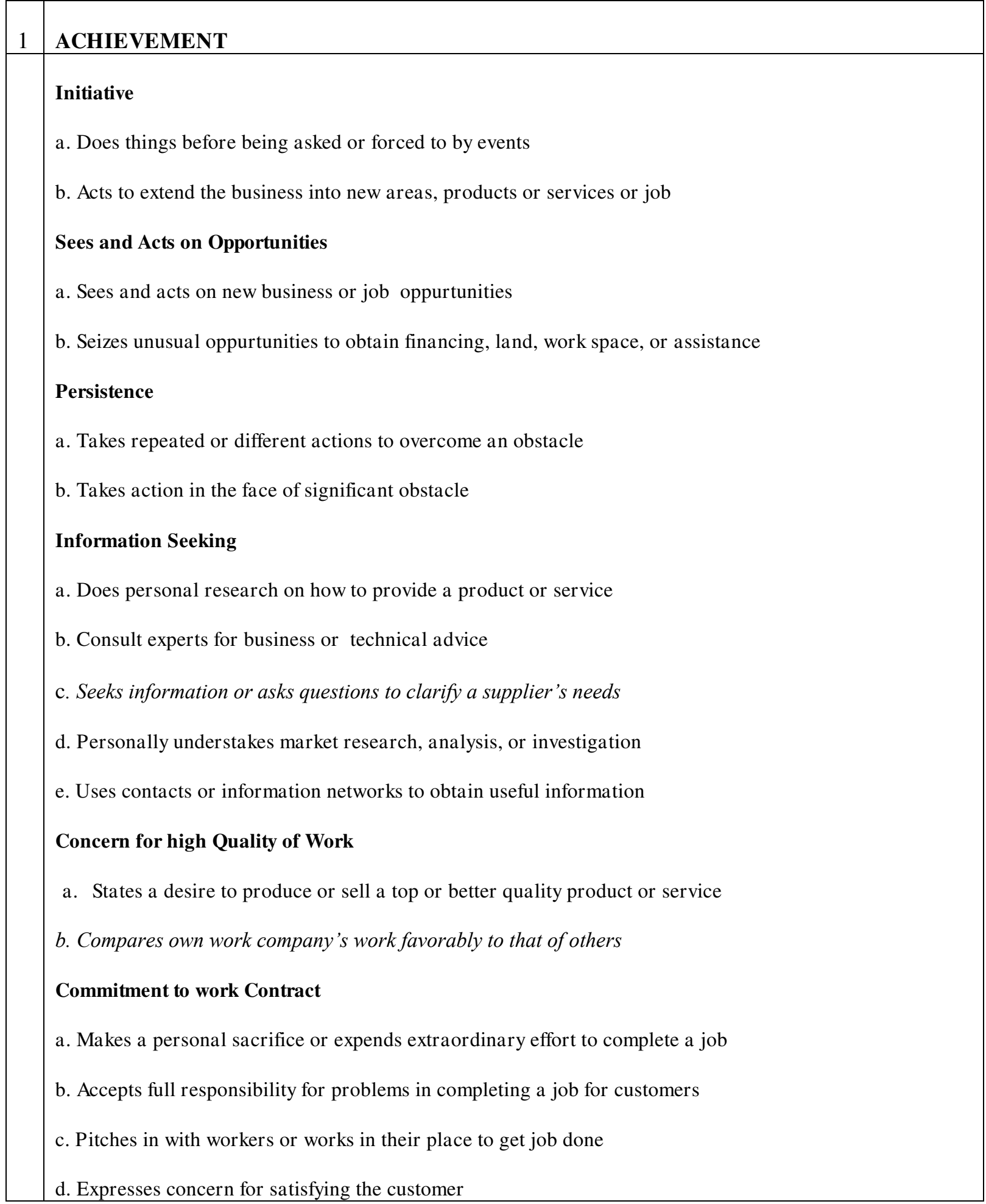




\section{Efficiency Orientation}

a. Looks for or finds ways to do things faster or at less cost

b. Uses information or business tools to improve efficiency

c. Expresses concern about costs vs. benefits of some improvement, change, or course of action

2 THINKING AND PROBLEM SOLVING, INCLUDE : SYSTEMATIC PLANNING, PROBLEM SOLVING

\section{Systematic Planning}

a. Plans by breaking a large task down into subtasks

b. Develops plans that anticipate obstacles

c. Evaluates alternatives

d. Takes a logical and systematoc approach to activities

\section{Problem Solving}

a. Switches to an alternative strategy to reach a goal

b. Generates new ideas or innovative solutions

3 PERSONAL MATURITY

\section{Self- Confidence}

a. Expresses confidence in his or her own ability to complete a task or meet a challenge

b. Sticks with his or her own judgment in the face of opposition or early lack of success

c. Does something that he or she says is risky

\section{Expertise )}

a. Had experience in the same area of business

b. Possesses strong technical expertise in area of business

c. Had skill in finance before starting business

d. Had skill in accounting before starting business

e. Had skill in production before starting business

f. Had skill in marketing/selling before starting business

g. Had skill in other relevant business area before starting business 


\begin{tabular}{|c|c|}
\hline & $\begin{array}{l}\text { a. Explicitly states a personal limitation } \\
\text { b. engages in activities to improve own abilities } \\
\text { c. states learning from a past mistake }\end{array}$ \\
\hline 4 & INF LUENCE \\
\hline & $\begin{array}{l}\text { Persuasion } \\
\text { a. Convinces someone to buy a product or service } \\
\text { b. Convinces someone to provide financing } \\
\text { c. Convinces someone to do something else that he or she would like that person to do } \\
\text { d. Asserts own competenve, reliability, or other personal or company qualities } \\
\text { e. Asserts strong confidence in own company's product or services } \\
\text { Use of Influence Strategies } \\
\text { b. Usts to develop business contacts } \\
\text { c. Selectively limits the information given to others } \\
\text { d. Uses a strategy to influence or persuade others }\end{array}$ \\
\hline 5 & DIRECTING AND CONTROLLING \\
\hline & $\begin{array}{l}\text { Assetiveness } \\
\text { a. Confronts problem with others directly } \\
\text { b. Tells others what they have to do } \\
\text { c. Reprimands or disciplines those failing to perform as expected } \\
\text { Monitoring } \\
\text { a. Develops or uses procedures to ensure that works is completes or that work meets standards of quality } \\
\text { b. Personally supervises all aspects of a project }\end{array}$ \\
\hline 6 & ORIENTATION TO OTHERS \\
\hline & $\begin{array}{l}\text { Credibility, integrity and Sincerity } \\
\text { a. Emphasizes own honest to others (e.g. in selling) } \\
\text { b. Acts to ensure honesty or fairness in delaing with others } \\
\text { c. Follows through on rewards and sanctions (to employees, suppliers) }\end{array}$ \\
\hline
\end{tabular}


d. Tells customer he or she cannot do something (e.g. complete a task) even if it means a loss of business

\section{Concern for Employee Walfare}

a. Takes action to improve the walfare of employees

b. Takes positive action in response to employee' personal concerns

c. Expresses concern about the walfare of employees

Recognizing the importance of business relationship

a. Sees interpersonal relationship as a fundamental business resource

b. Places long-term good will over short-term gain in a business relationship

c. Emphasizes importance of maintaining cordiality or correct bahvior at all times with the customer

d.Acts to built rapport or friendly relationship with customer

Dari penelitian ini dikembangkan hipotesis sebagai berikut : Terdapat perbedaan kompetensi yang signifikan yaitu kompetensi "Achievement, Thingking and Problem Solving, Personal Maturity, Directing and Controlling, Orientation to Others, Influence” antara pengusaha kuliner yang memiliki kinerja unggul dan kinerja biasa/rata rata .

\section{Metode Penelitian}

Penelitian Kuantitaif ini dilakukan dengan survei untuk mengidentifikasi kompetensi baik yang bersifat manajerial maupun keterampilan \& pengetahuan melalui CBI (Competency Based Interview), observasi dengan mengambil sampel pengusaha kuliner yang melayani pemesanan karena suatu "event" dikota Bandung. Jumlah Sampel terpilih sejumlah 18 pengusaha yang didominasi oleh kaum perempuan dengan kriteria merupakan sampel yang berkinerja baik yaitu berdasarkan informasi beberapa pemakai usaha kuliner/katering (sering digunakan pada suatu event resepsi, seminar dan beberapa bentuk event lainnya). Teknik pengumpulan data dilakukan melalui terhadap sampel dengan melakukan wawancara yang berbasis kompetensi untuk mendapatkan kompetensi apa saja yang dibutuhkan atau menyebabkan mereka berhasil memilki kinerja unggul. Dipilih menggunakan wawancara/interview adalah melihat karakteristik pengusaha bahwa mereka lebih bebas berbicara dan mengekspresikan keberhasilannya dari pada harus menulis dan tidak seluruhnya bisa diungkapkan dalam tulisan. Selanjutnya temuan Kompetensi yang menyebabkan keberhasilan atau kinerja unggul dilakukan identifikasi untuk CBL ( Competency Based Learning )

\section{BEI (Behavioral Event Interview) atau CBI}

Merupakan salah satu metode dan alat ukur yang digunakan dalam pengukuran kompetensi. Wawancara Competency Based Interview (CBI) merupakan salah satu metode yang terstandarisasi dan efektif untuk menggali kompetensi individu 1, yang dilakukan melalui percakapan mendalam, untuk menilai acceptability Individu pada suatu tuntutan kondisi atau persyaratan terkait pekerjaan atau hal lain yang telah ditentukan Keunggulan CBI, antara lain: 
1. Metode wawancara dirancang untuk mendapatkan bukti perilaku dan prestasi kerja. Data yang diperoleh dari CBI sangat kaya dan dapat dijadikan hipotesa yang memprediksi tampilan kerja superior pada job tertentu.

2. Evaluasi komprehensif terhadap hasil interview akan merefleksikan kompetensi yang dimiliki dan kompetensi yang tidak dimiliki oleh individu.

Pengolahan data kompetensi dari responden diolah untuk mengelompokkan pengusaha kuliner Kinerja superior dan kinerja rata rata dengan menggunakan statistik Hierarchical Cluster Analysis SPSS untuk memperoleh kelompok pengusaha mana yang kinerja unggul dan rata rata dari 18 responden. Untuk mengetahui apakah ada perbedaan antara nilai kompetensi pengusaha yang unggul dengan kompetensi pengusaha rata-rata, dilakukan uji beda rataan dengan Mann Whitney/Wilcoxon. Dari hasil pengujian tersebut juga dapat diketahui profil kompetensi yang membedakan pengusaha kuliner unggul dengan pengusaha rata-rata.

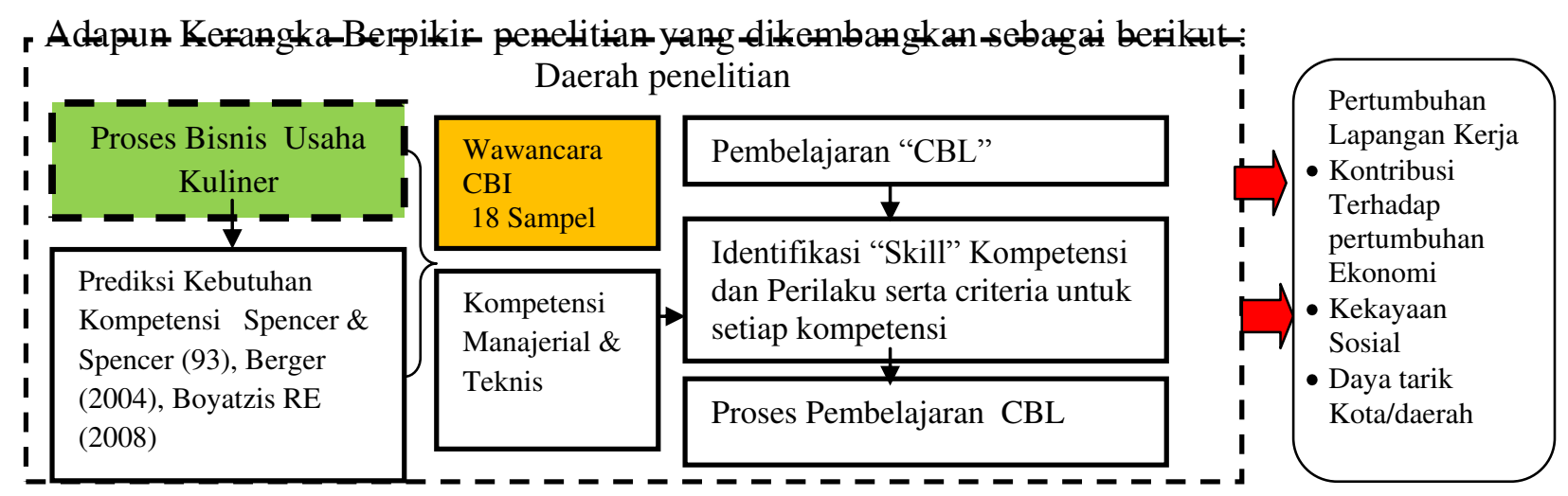

Gambar 3. Kerangka Berpikir Penelitian

\section{Operasionalisasi Variabel}

\section{Variabel kompetensi “entrepreneurship" dikembangkan dari model Spencer ( 1993) dan}

WEI-WEN WU (2009) dalam A competency-based model for the success of an entrepreneurial start-up , untuk kompetensi teknis terkait pengetahuan dan ketrampilan kuliner dikembangkan dari adopsi Hu,M.L (2010), Discovering Culinary Competency, sebagai berikut :

Tabel 3. Operasionalisasi Variabel

\begin{tabular}{|c|c|c|c|}
\hline No & $\begin{array}{c}\text { Kelompok } \\
\text { Kompetensi }\end{array}$ & Kompetensi & Indikator Perilaku \\
\hline \multirow[t]{5}{*}{1} & \multirow[t]{5}{*}{ Achievement } & \multirow[t]{3}{*}{ Proaktif } & Memiliki target \\
\hline & & & Mengantisipasi \\
\hline & & & Menyesuaikan produk \& layanan \\
\hline & & \multirow[t]{2}{*}{ Kualitas Kerja } & Pengawasan kualitas \\
\hline & & & $\begin{array}{l}\text { Menggunakan teknologi informasi dan telekomunikasi dalam } \\
\text { menjalankan usaha katering ( web, HP. Telp, Internet) }\end{array}$ \\
\hline
\end{tabular}




\begin{tabular}{|c|c|c|c|}
\hline & & & $\begin{array}{l}\text { Menggunakan peralatan serta bahan makanan dan minuman yang } \\
\text { kualitas lebih baik }\end{array}$ \\
\hline & & \multirow[t]{2}{*}{$\begin{array}{l}\text { Melihat dan } \\
\text { Membaca Peluang }\end{array}$} & $\begin{array}{l}\text { Menyediakan variasi fasilitas jasa lain selain catering demi } \\
\text { layanan }\end{array}$ \\
\hline & & & $\begin{array}{l}\text { Melakukan terobosan baru dalam pelayanan dan siap menerima } \\
\text { keluhan }\end{array}$ \\
\hline & & \multirow[t]{2}{*}{ Efisiensi } & $\begin{array}{l}\text { Pemesanan atau transaksi dengan pihak pemasok menggunakan } \\
\text { fasilitas komunikasi }\end{array}$ \\
\hline & & & Pengelolaan keuangan dilakukan secara efisien \\
\hline & & \multirow[t]{3}{*}{ Mencari Informasi } & Mencari informasi dari berbagai media \\
\hline & & & Ikut serta dalam wadah organisasi (misal: APJI) \\
\hline & & & $\begin{array}{l}\text { Secara khusus mempelajari hal-hal yang berkaitan dalam } \\
\text { menjalankan usaha catering }\end{array}$ \\
\hline & & \multirow[t]{3}{*}{$\begin{array}{l}\text { Komitmen pada } \\
\text { Pekerjaan }\end{array}$} & $\begin{array}{l}\text { Menetapkan pembayaran down payment disesuaikan dengan tipe } \\
\text { konsumen }\end{array}$ \\
\hline & & & $\begin{array}{l}\text { Menjaga kepercayaan dan komitmen terhadap konsumen dalam } \\
\text { memberikan pelayanan }\end{array}$ \\
\hline & & & Rajin mengulang-ulang resep menjadi lebih bernilai tambah/laku \\
\hline \multirow[t]{6}{*}{2} & \multirow{6}{*}{$\begin{array}{l}\text { Thingking and } \\
\text { Problem } \\
\text { Solving }\end{array}$} & \multirow{3}{*}{$\begin{array}{l}\text { Membuat } \\
\text { Perencanaan Secara } \\
\text { Sistematis }\end{array}$} & Membuat catatan persiapan kegiatan \\
\hline & & & Membuat catatan (pembukuan) keuangan katering secara teratur \\
\hline & & & Memperhatikan dari hal kecil hingga kompleks \\
\hline & & \multirow[t]{3}{*}{$\begin{array}{l}\text { Menyelesai-kan } \\
\text { Masalah }\end{array}$} & $\begin{array}{l}\text { Mencari tau lebih rinci akibat dari permasalahan yang dihadapi } \\
\text { dan bagaimana solusinya }\end{array}$ \\
\hline & & & $\begin{array}{l}\text { Berbagi pengalaman dan saling membantu dengan pihak katering } \\
\text { lain }\end{array}$ \\
\hline & & & $\begin{array}{l}\text { Memberikan ekstra pelayanan pada konsumen, setelah melakukan } \\
\text { kekeliruan/kesalahan }\end{array}$ \\
\hline \multirow[t]{5}{*}{3} & \multirow[t]{5}{*}{$\begin{array}{l}\text { Personal } \\
\text { Maturity }\end{array}$} & \multirow[t]{3}{*}{ Percaya Diri } & $\begin{array}{l}\text { Percaya dan yakin akan kemampuan sendiri dapat menjalankan } \\
\text { bisnis katering, memberikan contoh-contoh produk kepada calon } \\
\text { pelanggan }\end{array}$ \\
\hline & & & $\begin{array}{l}\text { Mempertanggungjawabkan secara tuntas atas setiap } \\
\text { kekeliruan/kesalahan yang terjadi }\end{array}$ \\
\hline & & & $\begin{array}{l}\text { Menerima pesanan dari konsumen dengan variasi hidangan yang } \\
\text { lebih beragam }\end{array}$ \\
\hline & & \multirow{2}{*}{ Memiliki Keahlian } & Keahlian memasak ( perusahaannya) \\
\hline & & & $\begin{array}{l}\text { Memiliki kemampuan manajemen untuk menjalankan usaha } \\
\text { katering }\end{array}$ \\
\hline
\end{tabular}




\begin{tabular}{|c|c|c|c|}
\hline & & & $\begin{array}{l}\text { Ide sendiri menyesuaikan hidangan dan dekorasi dengan tema } \\
\text { acara, minat konsumen, biaya dan lokasi }\end{array}$ \\
\hline \multirow[t]{2}{*}{4} & \multirow[t]{2}{*}{$\begin{array}{l}\text { Directing and } \\
\text { Controlling }\end{array}$} & \multirow[t]{2}{*}{$\begin{array}{l}\text { Kepemimpi-nan dan } \\
\text { Pengawasan }\end{array}$} & $\begin{array}{l}\text { Memberikan kepercayaan, bimbingan dan arahan kepada para } \\
\text { karyawan saat bekerja }\end{array}$ \\
\hline & & & Memperlakukan semua karyawan secara adil \\
\hline \multirow[t]{12}{*}{5} & \multirow[t]{12}{*}{$\begin{array}{l}\text { Orientation to } \\
\text { Others }\end{array}$} & \multirow[t]{3}{*}{$\begin{array}{l}\text { Dapat Dipercaya, } \\
\text { Jujur dan Tulus }\end{array}$} & $\begin{array}{l}\text { Terbuka dan tulus dalam memberikan pelayanan terhadap } \\
\text { konsumen seperti hobi }\end{array}$ \\
\hline & & & $\begin{array}{l}\text { Tepat waktu dan optimal dalam memberikan pelayanan terhadap } \\
\text { konsumen sesuai janji }\end{array}$ \\
\hline & & & $\begin{array}{l}\text { Memberikan gaji yang sesuai dengan kinerja karyawan dan tepat } \\
\text { waktu }\end{array}$ \\
\hline & & \multirow[t]{3}{*}{$\begin{array}{l}\text { Kepedulian terhadap } \\
\text { Orang Lain }\end{array}$} & $\begin{array}{l}\text { Melakukan diskusi terlebih dahulu dengan pihak konsumen untuk } \\
\text { mencapai kesepakatan }\end{array}$ \\
\hline & & & $\begin{array}{l}\text { Memberikan bantuan bila ada karyawan yang membutuhkan atau } \\
\text { menghadapi kesulitan }\end{array}$ \\
\hline & & & Memberlakukan insentif dan bonus kepada karyawan atas prestasi \\
\hline & & \multirow{3}{*}{$\begin{array}{l}\text { Mengakui } \\
\text { Pentingnya } \\
\text { Hubungan Bisnis }\end{array}$} & $\begin{array}{l}\text { Mengadakan kegiatan rekreasi bersama karyawan dan } \\
\text { keluarganya }\end{array}$ \\
\hline & & & $\begin{array}{l}\text { Memberikan bingkisan/hadiah kepada konsumen (misal saat } \\
\text { ultah) }\end{array}$ \\
\hline & & & Menjaga hubungan baik dengan konsumen \& pemasok \\
\hline & & \multirow{3}{*}{$\begin{array}{l}\text { Mengem-bangkan } \\
\text { Prestasi Orang Lain }\end{array}$} & Sharing informasi kepada pihak pemasok makanan \\
\hline & & & Memfasilitasi karyawan untuk meningkatkan kinerja \\
\hline & & & Mempunyai karyawan tetap \\
\hline \multirow[t]{7}{*}{6} & \multirow[t]{5}{*}{ Influence } & \multirow{2}{*}{$\begin{array}{l}\text { Persuasif } \\
\text { Interpersonal }\end{array}$} & $\begin{array}{l}\text { Hubungan kekeluargaan dengan karyawan, pihak pemasok \& } \\
\text { mitra }\end{array}$ \\
\hline & & & Mengajak kebersamaan dalam pelayanan \\
\hline & & \multirow{3}{*}{$\begin{array}{l}\text { Mengguna-kan } \\
\text { Strategi Membujuk }\end{array}$} & Mengundang calon konsumen untuk mencoba sebelum kontrak \\
\hline & & & $\begin{array}{l}\text { Meyakinkan calon konsumen untuk menggunakan jasa } \\
\text { kulinernya }\end{array}$ \\
\hline & & & Memahami dengan professional pelayanan jasa catering lain \\
\hline & $\begin{array}{l}\text { Kelompok } \\
\text { Kompetensi } \\
\text { Teknis }\end{array}$ & Kompetensi & \\
\hline & & Teknik Kuliner & Cara penyimpanan \& pengawetan makanan \\
\hline
\end{tabular}




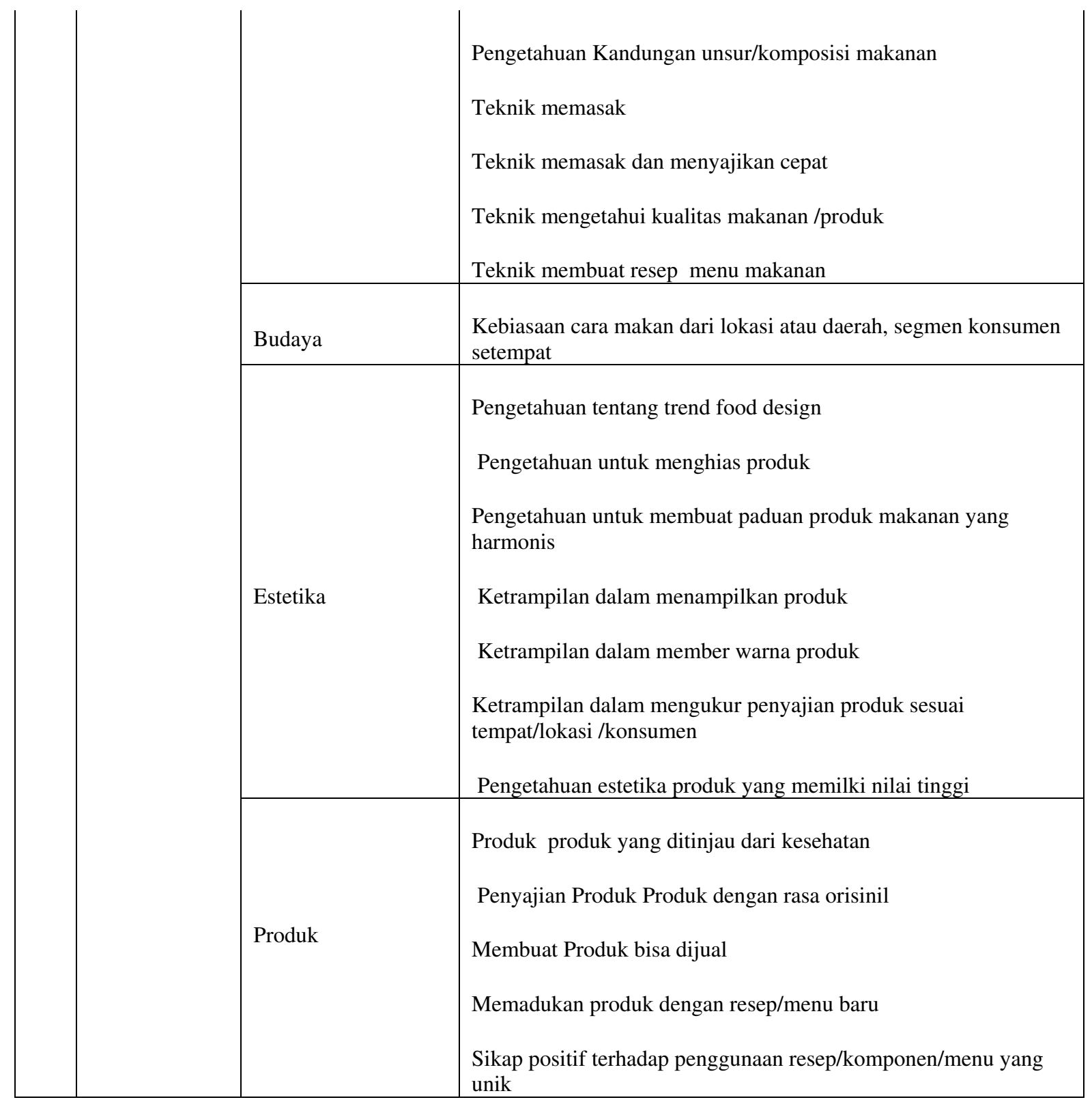




\section{HASIL DAN PEMBAHASAN}

Hasil olah data untuk pengelompokan kompetensi yang dilakukan dengan SPSS non parametric sebagai berikut :

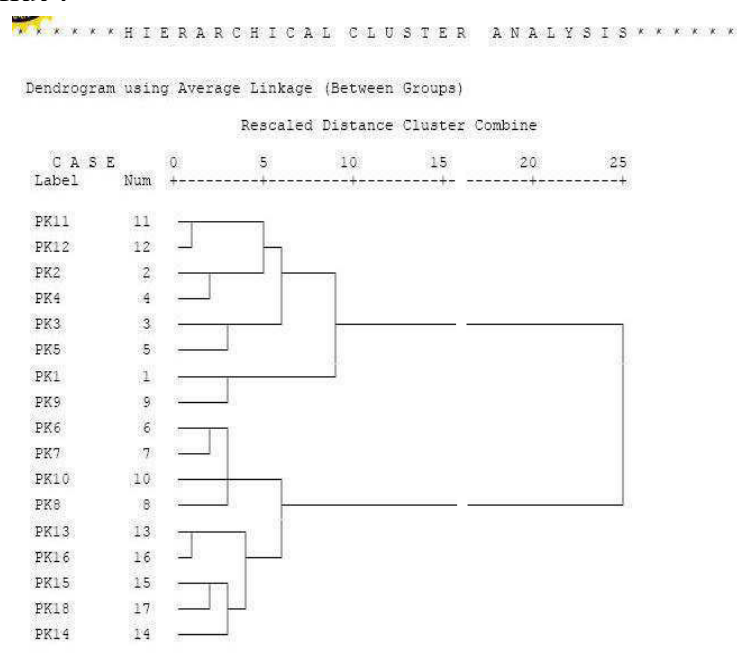

\begin{tabular}{|c|c|}
\hline $\begin{array}{c}\text { Kelompok } \\
\text { Pengusaha } \\
\text { Berkinerja } \\
\text { Unggul }\end{array}$ & $\begin{array}{c}\text { Kelompok } \\
\text { Pengusaha } \\
\text { Berkinerja } \\
\text { Rata-rata }\end{array}$ \\
\hline PK 1 & PK 6 \\
PK2 & PK 7 \\
PK3 & PK8 \\
PK4 & PK18 \\
PK5 & PK10 \\
PK9 & PK13 \\
PK11 & PK14 \\
PK12 & PK15 \\
& PK16 \\
& PK17 \\
\end{tabular}

Tabel 4.. Hasil Kelompok Pengusaha

Gambar 4. Hasil Pengelompokan dengan Hierarchical Cluster Analysis

Tabel 5. menunjukkan hasil uji beda rataan untuk kompetensi dari 2 kelompok tersebut. Variabel kompetensi yang memiliki signifikansi $<0,05$ mengandung arti bahwa terdapat perbedaan kompetensi antara kelompok pengusaha kuliner kinerja unggul dan pengusaha kuliner kinerja rata rata atau hipotesis teruji .

Tabel 5. Hasil Uji Beda Rataan dengan Uji Mann Whitney/Wilcoxon

\begin{tabular}{|c|c|c|}
\hline Kompetensi & Nilai Signifikansi & $\begin{array}{c}\text { Arti } \\
\text { Bila }>\alpha=0,05\end{array}$ \\
\hline Pro Aktif & $\mathbf{0 , 0 0}$ & Beda \\
\hline Kualitas Kerja & $\mathbf{0 , 0 0}$ & Beda \\
\hline Membaca peluang & 0,001 & Beda \\
\hline Efisiensi & 0,277 & Tidak \\
\hline Pencarian Informasi & 0,37 & Tidak \\
\hline Komitmen Terhadap Pekerjaan & $\mathbf{0 , 0 0}$ & Beda \\
\hline Perencanaan \& Implementasi & $\mathbf{0 , 0 0}$ & Beda \\
\hline Penyelesaian Masalah & 0,167 & Tidak \\
\hline Percaya Diri & $\mathbf{0 , 0 0 1}$ & Beda \\
\hline Keahlian & $\mathbf{0 , 0 0 1}$ & Beda \\
\hline Kepemimpinan \& Pengawasan & $\mathbf{0 , 0 0 1}$ & Beda \\
\hline Dapat Dipercaya, Jujur, Tulus & 0,002 & Beda \\
\hline Peduli dengan Orang lain & 0,815 & Tidak \\
\hline Memahami Pentingnya Hubungan Bisnis & $\mathbf{0 , 0 0 1}$ & Beda \\
\hline Orientasi prestasi orang lain & 0,673 & Tidak \\
\hline Persuasif & 0,004 & Beda \\
\hline Menggunakan Strategi Membujuk & 0,000 & Beda \\
\hline
\end{tabular}

Hasil Olah data uji beda rataan ,Sumber: Nur Fitricia F (2011)

Dari hasil tabel 5, Kompetensi dengan nilai signifikansi $<0,05$ berarti merupakan kompetensi pembeda (differentiating competencies ), demikian hipotesis teruji. 
Tabel 6. Hasil interview Kompetensi teknis bagi kelompok pengusaha Kuliner dengan Kinerja Unggul

\begin{tabular}{|c|c|}
\hline Kompetensi teknis & Hasil Rangkuman Kompetensi Teknis \\
\hline Teknik Kuliner & $\begin{array}{l}\text { Teknik manajemen pengadaan, menghitung “ Lead Time” dan manajemen waktu } \\
\text { Pengetahuan Produk, Bahan baku, kandungan bahan baku } \\
\text { Teknik "cooking” \& memadukan resep, menu . }\end{array}$ \\
\hline Budaya & $\begin{array}{l}\text { Memahami kebiasaan, tata cara makan suatu daerah /lokasi maupun segmen konsumen dari sisi } \\
\text { umur maupun tingkat ekonomi dan pekerjaannya. }\end{array}$ \\
\hline Estetika & $\begin{array}{l}\text { Memilki Pengetahuan dan teknik estetika tentang trend food, membuat produk menarik } \\
\text { Sesuai segmen konsumen, menghias produk, paduan produk makanan yang harmonis } \\
\text {, Ketrampilan dalam memberi warna produk, estetika produk yang memilki nilai tinggi }\end{array}$ \\
\hline Produk & $\begin{array}{l}\text { Produk produk yang ditinjau dari kesehatan, unik, penyajian produk dengan rasa orisinil } \\
\text { Membuat Produk bisa dijual, substitusi bahan baku sesuai dengan konsumen }\end{array}$ \\
\hline Makanan Sehat & Pengetahuan bahan baku makanan dan minuman dari sisi kesehatan \\
\hline
\end{tabular}

Sumber : Hasil olah data

\section{Hasil Penelitian}

Dari hasil olah data dapat diidentifikasi 6 kelompok Kompetensi dan 14 keterampilan manajerial/ Managerial Skills yang membedakan pengusaha kinerja superior dan kinerja rata rata , seperti ditunjukkan pada tabel 7. Hal ini dikuatkan oleh Ramo,L.G (2009) \& Berger.L.A (2004), menyatakan bahwa ada hubungan kuat antara kinerja dan kepemilikan kompetensi .

Tabel 7. Hasil Kompetensi yang membedakan pengusaha berhasil ( Berkinerja superior)

\begin{tabular}{|l|l|l|l|l|}
\hline Kompetensi & \multicolumn{3}{|c|}{ Skills } \\
\hline 1.Achievement \&Action & Proaktif & Kualitas Kerja & $\begin{array}{l}\text { Melihat } \begin{array}{c}\text { dan } \\
\text { Membaca Peluang }\end{array} \\
\text { Kemerjaan }\end{array}$ \\
\hline $\begin{array}{l}\text { 2.Thinking \& problem } \\
\text { solving }\end{array}$ & Perencanaan secara & sistematis \\
\hline 3.Directing and Controlling & Kepemimpinan dan Pengawasan & \\
\hline $\begin{array}{l}\text { 4.Orientation to Others } \\
\text { 5.Influence }\end{array}$ & Dapat Dipercaya & Hubungan Bisnis & Komitmen pada Pekerjaan \\
\hline $\begin{array}{l}\text { 6. Kompetensi } \\
\text { pengembangan diri } \\
\text { /Personal Maturity }\end{array}$ & Persuasive & Use of Influence Strategies (strategi membujuk) \\
\hline
\end{tabular}


Dari hasil olah data Kompetensi pembeda tabel 7, ke enam kelompok Kompetensi masing masik diuraikan dengan keterampilan manajerial atau "manajerial Skills" artinya pengusaha yang kompeten dapat menunjukkan secara nyata atau observable bukti perilaku yang terkait kompetensi tersebut ( Berger, L.A ,2004; Dreyfus, C.R ,2008; Ramo.L.G 2009 )

Untuk Kompetensi teknik tentang keahlian produk, pengetahuan tentang kuliner tidak harus pengusahanya kompeten tetapi organisasinya perlu memilki kompetensi tersebut. Untuk kompetensi teknis yang berupa pengetahuan dan ketrampilan kuliner hal ini mudah dilatihkan ataupun dikembangkan ( people skill ), namun untuk kompetensi keterampilan manajerial yang sifatnya "soft Skill" perlu dibelajarkan sehingga pengusaha secara terus menerus membangun kompetensi dirinya seperti Kompetensi "leadership" perlu dibangun ( Dreyfus,C.R. 2008).

Selanjutnya untuk perancangan pembelajaran berbasis kompetensi (CBL),dimaksudkan untuk membangun kompetensi manajerial. Isi pembelajaran CBL dapat dijelaskan dengan gambar 5 , yaitu kelompok kompetensi yang telah teridentifikasi ( Spencer, 93 ; Wu. 2009, yaitu Achievement \& Action, Thinking \& problem solving, Directing and Controlling, Orientation to Others, Influence, Personal Maturity, perlu diterjemahkan menjadi Skills yaitu Proaktif, Kualitas Kerja, Melihat dan Membaca Peluang, Komitmen pada Pekerjaan, Perencanaan Secara Sistematis, Dapat Dipercaya, Mengakui Hubungan Bisnis, Persuasive, Self awareness, Percaya diri, Keahlian Profesional. Keterampilan manajerial atau Skill disini berarti untuk mendemokan kompetensi tersebut yaitu merupakan tindakan/perilaku yang "observable" yang dalam pembelajaran ini disebut sebagai "Learning Behavior". Untuk memenuhi Learning Behavior bagi pembelajar maka di identifikasi pelajaran apa saja yang diperlukan selanjutnya evaluasi peserta pembelajaran dilakukan dengan Competency Based Assessment (CBA). Dan proses pembelajaran dilakukan dengan metode experiental Learning. Tahapan CBL dapat ditunjukkan pada gambar 5 dan contoh identifikasi kompetensi menjadi CBL pada tabel 8 : 
"Competency based learning" : Method To Translate new competencies \& Skills into Curricula Once competencies, skills and actions are defined, they must be integrated, applied, and assessed within a course design.
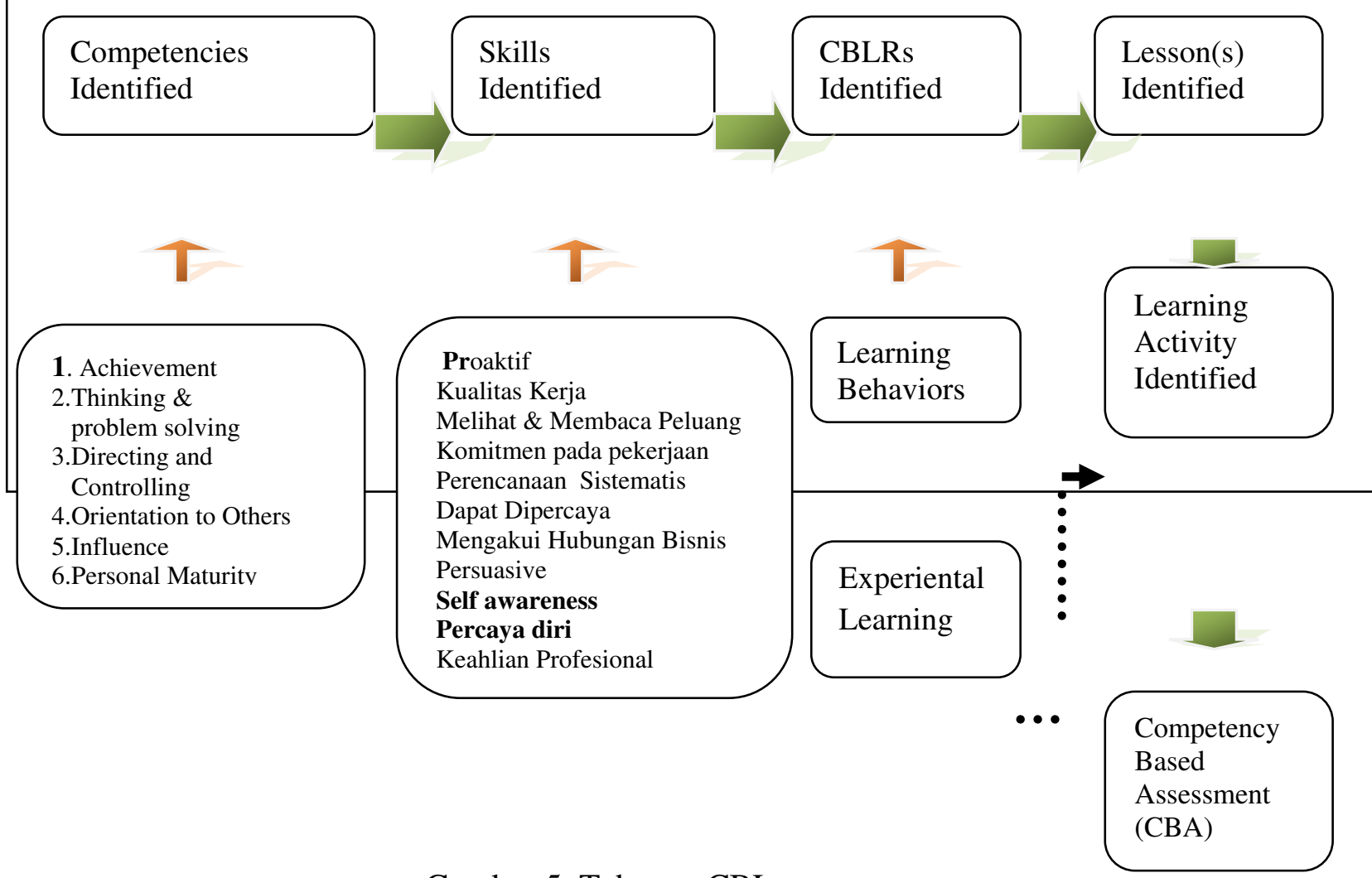

Gambar 5. Tahapan CBL

Model diadopsi dengan pendekatan dari:SAF Centre for Leadership http://www.mindef.gov.sg/imindef/mindef_websites/atozlistings/ 
Table 8.Competency Based Learning Requirement CBLR(s)

\begin{tabular}{|c|c|c|c|}
\hline Competency & Skill & CBLR & Lesson(s) \\
\hline \multirow[t]{2}{*}{ Influence } & $\begin{array}{l}\text { Persuasif } \\
\text { Interpersonal } \\
\text { 'Persuasion" }\end{array}$ & $\begin{array}{l}\text { Memilki hubungan baik } \\
\text { - Memilki kontrak kerja dengan } \\
\text { karyawan, mitra bisnis, sub } \\
\text { kontraktor } \\
\text { Melakukan tindakan persuasif } \\
\text {-Teknik yang efektif seperti } \\
\text { mendengarkan secara aktif dan } \\
\text { interpretasi isyarat non -verbal } \\
\text {-Budaya komunikasi terbuka } \\
\text { dengan membangun dan membina } \\
\text { saluran komunikasi } 2 \text { arah. }\end{array}$ & \multirow[t]{2}{*}{$\begin{array}{l}\text { 1.Manajemen Team work } \\
\text { 2.Relasi dengan Orang lain } \\
\text { 3.Teknik Komunikasi } \\
\text { untuk mempengaruhi } \\
\text { 4.Teknik Memotivasi } \\
\text { 5.Teknik Negosiasi } \\
\text { Competency Based } \\
\text { Assessment (CBA) }\end{array}$} \\
\hline & $\begin{array}{l}\text { Mengguna-kan } \\
\text { Strategi } \\
\text { Membujuk } \\
\text { "Use of Influence } \\
\text { Strategies" }\end{array}$ & $\begin{array}{l}\text { Mengajak pelanggan } \\
\text { menggunakan serangkaian } \\
\text { pengaruh tidak langsung. } \\
\text { - Bertindak memahami kebutuhan } \\
\text { pelanggan } \\
\text { - Memotivasi pemasok, } \\
\text { subkontraktor lain agar } \\
\text { membuat layanan \& produk } \\
\text { baru } \\
\begin{array}{l}\text { Negosiasi secara aktif dengan } \\
\text { orang lain untuk mencapai hasil } \\
\text { yang dapat diterima }\end{array}\end{array}$ & \\
\hline
\end{tabular}

( Model diadopsi dengan pendekatan dari :SAF Centre for Leadership http://www.mindef.gov.sg/imindef/mindef_websites/atozlistings/)

Isi pembelajaran diidentifikasi melalui CBLR(s), sedangkan cara cara pembelajaran dilakukan dengan metoda Experiental Learning dikembangkan oleh David Kolb sekitar awal 1980-an. yaitu :

Merupakan model pembelajaran orang dewasa yang dapat menciptakan proses belajar yang bermakna, pembelajar mengalami apa yang mereka pelajari. Hasil dari proses pembelajaran "experiential learning(EL") ini mengaktifkan pembelajar untuk membangun pengetahuan dan keterampilan melalui pengalamannya secara langsung. Tujuannya "EL" untuk mempengaruhi pembelajar melalui 3 hal, yaitu; 1) mengubah struktur kognitif, 2) mengubah sikap dan 3) memperluas keterampilan-keterampilan. Menurut experiential learning theory, agar proses belajar mengajar efektif, ada 4 kemampuan 
Table 9. Kemampuan dalam Experiential Learning

\begin{tabular}{|l|l|l|}
\hline \multicolumn{1}{|c|}{ Kemampuan } & \multicolumn{1}{|c|}{ Deskripsi } & \multicolumn{1}{|c|}{ Penggunaan } \\
\hline Concrete Experience (CE) & Belajar dengan melibatkan diri dalam pengalaman baru & Feeling (perasaan) \\
\hline Reflection Observation (RO) & $\begin{array}{l}\text { Belajar dengan mengobservasi \& merefleksikan atau } \\
\text { memikirkan pengalaman dari berbagai aspek }\end{array}$ & $\begin{array}{l}\text { Watcing } \\
\text { (mengamati) }\end{array}$ \\
\hline $\begin{array}{l}\text { Abstract Conceptualization } \\
\text { (AC) }\end{array}$ & $\begin{array}{l}\text { Belajar menciptakan konsep-konsep yang dari suatu } \\
\text { observasi menjadi teori }\end{array}$ & Thinking (berpikir) \\
\hline Active Experimentation (AE) & $\begin{array}{l}\text { Belajar menggunakan teori untuk memecahkan masalah- } \\
\text { masalah dan pengambilan keputusan }\end{array}$ & Doing (berbuat) \\
\hline
\end{tabular}

Sumber : Modifikasi dari http://albyjmahfudz.blogspot.com/2011/05/model-pembelajaran-experiential.html

Konsep William Glaser, Educational Psychologist dalam different modes of Learning , dalam penggunaan proses pembelajaran maka prosentase penyerapan hasilnya sebagai bereikut :

\begin{tabular}{|l|l|}
\hline What we read & $10 \%$ \\
\hline What we hear & $20 \%$ \\
\hline What we see & $30 \%$ \\
\hline What we see/hear & $50 \%$ \\
\hline & \\
\hline What we discuss with others & $\mathbf{7 0 \%}$ \\
\hline & \\
\hline What we experience & $80 \%$ \\
\hline & $\mathbf{9 5 \%}$ \\
\hline
\end{tabular}

http://principalcowart.blogspot.com/2009/02/how-we-learn-william-glasser.html

Bagaimanapun proses pembelajaran maupun pengembangan diharapkan kompetensi pengusaha bisa sebagai pemimpin dapat mengelola enerji dirinya dan lingkungan usaha sekitarnya, enerji dimaksud adalah seberapa besar dengan modal kompetensi pengusaha melibatkan dirinya secara fisik, mental, spritual maupun sosial didalam lingkungan kerja ( Losey, M \& Ulrich , D .2005. Pemimpin Usaha memiliki peran penting dalam mengeksekusi kegiatan kuliner (Kusumastuti, D ,2013).

Selanjutnya mengingat Indonesia adalah luas dan beragam budaya maupun jenis kuliner maka dalam hasil penelitian ini peneliti mengusulkan agar pengembangan dan pembangunan kompetensi menjadi bagian dari pemberdayaan yang dilakukan oleh pemerintah daerah yaitu program pemberdayaan pengusaha kuliner. Hal ini agar sekaligus merangsang motivasi calon pengusaha. Sesuai dari kluster Industri kreatif Indonesia, jenis kuliner masuk pada kluster 
kepariwisataan, yang artinya memilki nilai tambah yang menantang serta "talent" ini selalu dapat diperbaharuhi mengingat Inovasi menjadi kunci kelanggengan usaha. .

Sedangkan kompetensi teknis yang perlu dimiliki sebagai pengusaha kuliner adalah intinya adalah teknik kuliner dengan inovasi produk dengan melibatkan budaya dan estetika. Hal ini menyatakan bahwa kuliner bukan saja masalah makan tetapi merupakan industry ataupun produk produk kreatif.

\section{Kesimpulan}

Penelitian ini berhasil menemukan bahwa terdapat perbedaan antara profil kompetensi pengusaha kuliner dengan kinerja unggul dengan pengusaha kuliner kinerja rata rata-rata. Secara umum yaitu kompetensi tersebut adalah Orientasi prestasi, Berpikir dan penyelesaian masalah, Kedewasaan dalam bekerja, Pengarahan dan pengawasan, Orientasi pada perhatian orang lain serta dapat Mempengaruhi .

Pembelajaran dari Kompetensi ( $\mathrm{CBL}$ ) bagi pengusaha kuliner dilakukan dengan menguraikan kelompok kompetensi menjadi keterampilan kompetensi manajerial selanjutnya dianalisis perilaku perilaku yang dibutuhkan oleh pengusaha kuliner menjadi materi pembelajaranserta evaluasi pembelajaran dilakukan dengan CBA, yaitu apakah pembelajar sudah memenuhi kompetensi yang dibutuhkan tersebut. Isi CBL tersebut dibelajarkan dengan cara /metode pembelajaran / pelatihan dengan pembelajaran orang dewasa yaitu belajar dengan melibatkan diri dalam pengalaman baru ( perasaan ), mengobservasi \& merefleksikan (mengamati), menciptakan konsep-konsep yang dari suatu observasi menjadi pengetahuan ( berpikir), memecahkan masalah-masalah untuk pengambilan keputusan ( berbuat). Kompetensi perlu dikembangkan dan dibangun pada diri pengusaha kuliner mengingat usaha ini bertumpu pada persaingan dan kekuatan berinovasi . Disamping kompetensi teknis kuliner juga penting. Pengembangan kompetensi dimulai dari tahap penyadaran, perbaikan /pelatihan kompetensi serta pembudayaan secara otomatis pengusaha menggunakan kompetensinya untuk menjalankan proyeknya. Sebagai percepatan pembelajaran hendaknya pemerintah menjadi inisiator untuk membangun pembelajaran kewirausahaan dibidang kuliner yang dapat diakses oleh semua calon pengusaha kuliner maupun pengusaha dimana diperlukan untuk pengembangan dan merangsang inovasi. Sehingga untuk memberdayakan pengusaha kuliner ini dibutuhkan pemimpin dari pemerintah yang kompeten menggerakkan inovasi sosial. .

\section{Implikasi Praktis :}

Setiap aspek pekerjaan dalam usaha kuliner, pemilik usaha biasanya merupakan pemimpin dalam perusahaan yang fungsinya adalah mempengaruhi, menggerakkan, dan membangkitkan kepercayaan dan loyalitas bawahannya. Maka nilai-nilai kompetensi ini sangat penting dimiliki dan diterapkan oleh setiap pengusaha yang ingin usahanya sukses dan bertahan lama.Disamping Kompetensi teknis perlu dimiliki dan selalu dikembangkan mengikuti dinamika kebutuhan. Kompetensi teknis ini relatif mudah dikembangkan dan bisa dibagi ke anggota organisasi penguasaannya. 


\section{DAFTAR REFERENSI}

Berger.L.A and Berger D. R.,eds. 2004. The Talent Management Handbook Creating Organizational Excellence by Identifying, Developing, and Promoting Your Best People, by The McGraw-Hill Companies, Inc. All rights reserved. Manufactured in the United States of America. 0-07-1414347.

Boyatzis, R.E.. 2008. Competencies in the 21 century, Journal of Management Development, Vol. 27 No. 1- 2008, pp.5-11.

BPS. 2012. Data Strategis BPS 2012. Badan Pusat Statistik CPT Psalm Lew. 2005. Preparing Leaders For The Complexities Of The Security Environment In The 21 'Century - SAF's Experience With Competency Based Learning, Centre of Leadership Development SAFTI Military Institute, Singapore . paper presented at the $41^{\text {st }}$ International Applied Military Psychology Symposium at Washington DC, USA May ,2005

Dreyfus, C.R.2008. Identifying competencies that predict effectiveness of R\&D managers", Philadelphia, Pennsylvania, USA, Journal of Management Development, Vol. 27 No. 1- 2008, pp.76-91.

Dyah,K dan Friday, FN. 2013, Model kompetensi manajerial \& teknis dan kebutuhan pelatihan bagi pengusaha kuliner yang sukses, Proceeding Strengthening The Strategy of Local Product in The Border Region: Opportunity and Challenges of The ASEAN Economic Community 2015, FMI ke 5 , Pontianak , 2013ISSN:2338-994X

Departemen Perdagangan RI,2008, Rencana Pengembangan Ekonomi Kreatif Indonesia 2009- 2015 , Studi Industri Kreatif Indonesia.

Friday Fitricia Nur ( 2011), Analisis Kompetensi Wirausaha sebagai faktor pendorong keberhasilan usaha jasa boga di Kota Bandung, jawa Barat, Thesis, Magister Manajemen Universitas Widyatama Bandung.

Henk Schout, Saskia Harkema, Entrepreneurial Learning: Practice as a Source for Learning and Business Success , Hague University of Applied Sciences, The Netherlands, Proceedings of the European Conference on Entrepreneurship \& Innovation is the property of Academic Conferences, http://hbo- kennisbank.uvt.nl/cgi/hh/show.cgi? fid=2269, Download December ,2013

Hu, M. L. (2010). Discovering Culinary Competency: An Innovative Approach. Journal of Hospitality, Leisure, Sport \& Tourism Education, Volume 9 (1), pp 65-72. ISSN 1473-8376, DOI:10.3794/Johlste.91.227

Http://principalcowart.blogspot.com/2009/02/how-we-learn-william-glasser.html, monday, february 16, 2009

Kusumastuti, D.2011, Aligning human resource and business strategy, International Conference, Widyatama University \& De LasalleLippa University Philippine, Proceeding, theme : Improving Business Competitiveness through Integrated System, ISBN:978-979-25-0221-3, pp A48-55 
Losey, M. M. S \& Ulrich D.2005, The future of Human Resource Management, 64 Thought Leaders Explore The Critical HR Issues of Today And Tomorrow, published by John Wiley \& Sons, Inc., ISBN 0-471-67791-4

Mahfudin.2011. Model pembelajaran experiential learning, http://albyjmahfudz.blogspot.com/2011/05/model-pembelajaran-experiential.html, diunduh 20 februari 2014

McLagan, P. (1996). Great ideas revisited. Training \& Development, 50(1), 60-65.

McLagan, P. (1997). Competencies: The next generation. Training \& Development, 51(5), 40-47.

Ramo L.G., Saris W E. and Boyatzis RE, 2009 , The impact of social and emotional competencies on effectiveness of Spanish executives, Journal of Management Development, Vol. 28 No. 9, 2009 pp. 771-793, Emerald Group Publishing Limited 0262-1711

Perkembangan Usaha Restoran/ Rumah Makan Berskala Menengah dan Besar Tahun 2007 -2010, diakses dari http://www.budpar.go.id/userfiles/file/rekaprestoran2007-2010.pdf

Perkembangan Usaha Restoran/ Rumah Makan Berskala Menengah Dan Besar Menurut Provinsi Tahun 2007

Peran strategis industri kuliner bagi pertumbuhan ekonomi, http://gopanganlokal.miti.or.id/index.php/peran-strategis-industri-kuliner-bagipertumbuhan-ekonomi

SAF Centre for Leadership http://www.mindef.gov.sg/imindef/mindef_websites/atozlistings/ saftimi/units/cld/keyideas/lcm,accessed 12 October 2012

Sanghi S.,( 2007), The Handbook of Competency Mapping, Understanding, Designing And Implementing Competency Models in Organizations, Second Edition Sage Publications Ltd, 1 Oliver's Yard, 55 City Road, London EC1Y 1SP, John Wiley \& Sons, Inc., ISBN 0-471 67791-4

Spencer, L.M \& Spencer. S.M , 1993, Competence At Work, John Wiley \& Sons, Inc, ISBN 0-47151809

Wei-Wen Wu . 2009. A competency-based model for the success of an entrepreneurial startup ,WSEAS TRANSACTIONS on BUSINESS and ECONOMICS , ISSN: 1109-9526 Issue 6, Volume 6, June, 2009

Wang, Z. 2003. "Managerial competency modelling and the development of organizational psychology: a Chinese approach", International Journal of Psychology, Vol. 38 No. 5, pp. 323-34. 